Article

\title{
Novel Micro-Mesoporous Composite ZSM-5 Catalyst for Aromatics Production by Catalytic Fast Pyrolysis of Lignin Residues
}

\author{
Wenbo Wang, Zhongyang Luo *(D), Simin Li, Shuang Xue and Haoran Sun \\ State Key Laboratory of Clean Energy Utilization, Zhejiang University, 38 Zheda Road, Hangzhou 310007, China; \\ cielaether@zju.edu.cn (W.W.); zju_lsm@zju.edu.cn (S.L.); 11727017@zju.edu.cn (S.X.); 11827079@zju.edu.cn (H.S.) \\ * Correspondence: zyluo@zju.edu.cn; Tel.: +86-571-8795-2440
}

Received: 5 March 2020; Accepted: 22 March 2020; Published: 1 April 2020

\begin{abstract}
The industrial utilization of lignocellulosic biomass is often accompanied by lots of lignin residues. Catalytic fast pyrolysis (CFP) is a high-throughput method to convert lignin to aromatics and phenolics. In order to optimize catalytic performance, conventional zeolite catalysts often need to have mesostructural modification. Here, based on hierarchical zeolite (HZ), a novel micro-mesoporous composite zeolite was obtained by redeposition under mild conditions. The conversion of two industrial lignin residues, Kraft Lignin (KL) and Pyrolytic Lignin (PL), was investigated. Interestingly, the hierarchical sample was more suitable for the case of higher concentration of primary pyrolysis products such as CFP of $\mathrm{PL}$, with aromatics yield of $12.7 \mathrm{wt} \%$ and a monocyclic aromatic hydrocarbons (MAHs) to polycyclic aromatic hydrocarbons (PAHs) mass ratio of 4.86. The mesoporous composite zeolite possessed a better PAHs suppression capability as M/P reached 6.06, and was suitable for low reactants' concentration and high oxygen content, such as KL CFP, with a higher aromatics yield of $3.3 \mathrm{wt} \%$ and $\mathrm{M} / \mathrm{P}$ of 5.12. These results were compared with poplar sawdust as actual biomass, and mesoporous samples were both highly efficient catalysts with MAHs yield over $10 \mathrm{wt} \%$ and M/P around 5 .
\end{abstract}

Keywords: catalytic fast pyrolysis; aromatics; Kraft lignin; pyrolytic lignin; composite zeolite

\section{Introduction}

In the current transformation of the energy sector, biomass as a renewable energy resource can provide a greener way to obtain chemicals and fuels [1,2]. Biomass utilization has a long history, such as in the paper industry, as well as for biodiesel production, fermentation to produce ethanol, biogas production, etc. Recently, fast pyrolysis has also been used to directly produce bio-oil [3]. However, when lignocellulosic biomass is used as a raw material, its lignin content is very problematic, bringing many problems-which include difficulties obtaining efficient conversion, affecting the yield of other components and increasing costs and potential pollution [4,5]. Some typical examples are alkali lignin in papermaking, heavy oil in fast pyrolysis, cellulolytic enzyme lignin in fermentation, and so on. The composition and structure types of these lignin residues are variable, and usually have increased C-C linkages and more nitrogen and sulfur. Many methods have been used for effective conversion, including hydrothermal depolymerization, supercritical ethanol depolymerization, pyrolysis, carbonization, etc. [6-9]. Among these, through in-situ CFP, the zeolite catalyst is physically mixed with raw materials, and the lignin residues or lignocellulosic biomass can be converted into aromatic hydrocarbons in one step [10-12]. Aromatics can be used as raw materials for chemical industry and medicine, and as additives for aviation fuel. However, except for the economic advantages of CFP, there are also accompanying problems, such as rapid deactivation of conventional catalysts, 
low carbon yield, excessive PAHs production, which affects fuel quality, and the need for a higher catalyst to biomass (C/L) ratio for certain products [13-15].

Common methods to modify catalysts include changing acidic and structural properties. Loading metals, such as $\mathrm{Ga}, \mathrm{Fe}, \mathrm{Mg}$, $\mathrm{Zr}$, etc., can reduce the strong acid sites on the catalysts' outer surface and increase the Lewis acid sites, thereby inhibiting the over-cracking to generate less gaseous products and higher bio-oil yield $[12,16,17]$. Textural properties are often optimized by using nano-sized particles and introducing mesoporous structure to increase specific surface area and enhance reactant diffusion $[16,18,19]$. For example, hierarchical zeolites (HZ) have been widely used recently [20,21]. Due to the intercrystalline mesopores in bulk particles and large openings on the particle surface, the diffusion performance is optimized. The acid sites' interiors have better accessibility for reactants, especially larger phenolic molecules, thereby improving the deoxygenation performance and preventing quick deactivation of the catalyst caused by coke covering surfaces. However, hierarchical ZSM-5 (Zeolite Socony Mobil-5) catalysts will lose valuable zeolites as raw materials during the desilication process. Further, an excessive base concentration will also partially destroy the shape-selectivity of micropore channels on light aromatics [22]. These disadvantages in catalyst cost and product quality will damage the practical feasibility for hierarchical zeolites application in lignin CFP. Therefore, more efforts on modification of hierarchical structure are needed to take full advantage of raw zeolite and optimize product distribution.

Here, a new composite mesopore catalyst was prepared by a redeposition method based on hierarchical ZSM-5. Current research is more focused on the individual components or real biomass, while there are few comparative studies on industrial lignin residues, and a lack of understanding of the scope of different zeolites' mesostructure. For this reason, Kraft lignin (KL) and pyrolytic lignin (PL) were used as two common lignin residues for CFP testing, to compare the catalytic performance of commercial ZSM-5, hierarchical ZSM-5 and composite mesoZSM-5. In order to further investigate their applicability, the product distributions at both low and high mixing ratios were also analyzed, especially focusing on the yield and selectivity of aromatics, phenolics and catechols. Further, the content of monocyclic aromatic hydrocarbons (MAHs) and polycyclic aromatic hydrocarbons (PAHs) among aromatics was taken as a parameter to evaluate the catalysts' shape-selectivity on heavy aromatics. In addition, poplar sawdust was selected as the representative of real lignocellulosic biomass for comparative reference. The effect of composite structural characteristics on catalytic performance was studied, and the applicable range of mesoporous structure was discussed.

\section{Results}

\subsection{Characterization Results}

The samples obtained by various preparation methods appear significantly different under TEM. The PZ (pristine ZSM-5) sample contains typical hexagonal particles with a size of about $2.5 \times 1 \mu \mathrm{m}$, measured from TEM and SEM images. After desilication under $0.2 \mathrm{M} \mathrm{NaOH}$, the hierarchical structure and breakage emerge distinctly. The $\mathrm{Si} / \mathrm{Al}$ inside the particles is relatively high, so more silica species are dissolved, retaining a well-demarcated particle edge. Further, internal channels have many funnel openings on the surface, with pore diameters larger than $20 \mathrm{~nm}$, as shown in Figure $1 \mathrm{~b}$. 

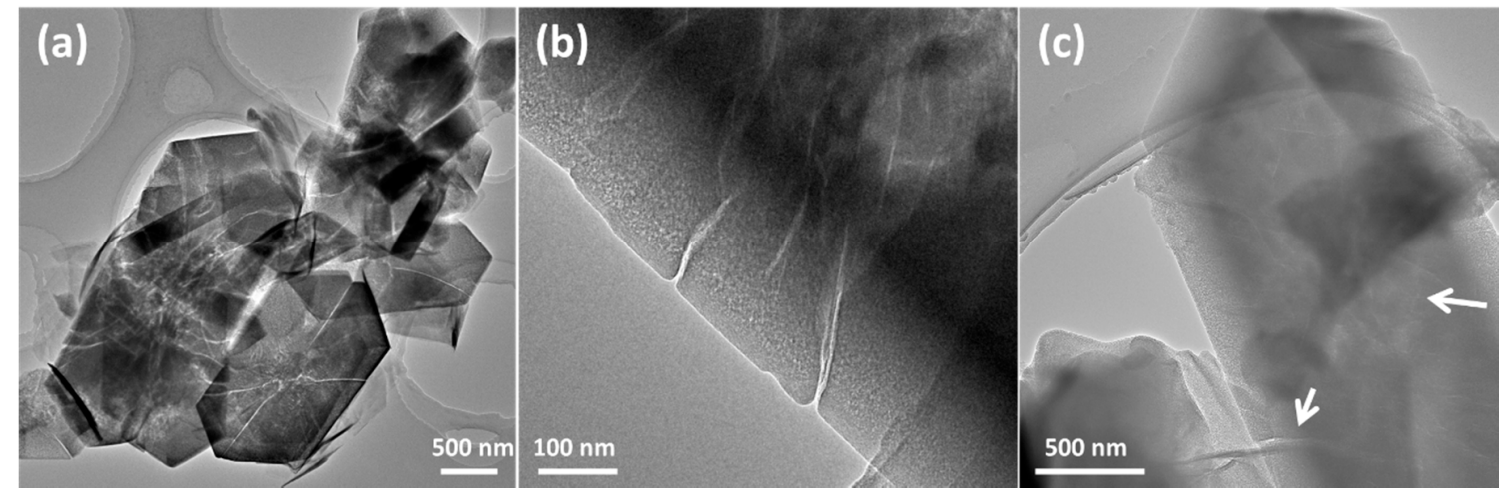

Figure 1. TEM images of mesostructured samples. (a) hierarchical zeolite (HZ); (b) enlargement of edge area of $\mathrm{HZ}$; (c) hierarchical mesoporous zeolite (HMZ).

The surface of the hierarchical mesoporous zeolite (HMZ) sample has obvious mesoporous morphology and the edges are relatively blurred. The synthesis scheme is similar with the Stöber method, and in this case, zeolite crystals dissolved in the $\mathrm{NaOH}$ solution acted as a silica source of sodium metasilicate [23]. After the diluted solution is neutralized to $\mathrm{pH}=7$ and a small amount of ammonia is added, the silica/hexadecyltrimethylammonium bromide (CTAB) micelles are able to self-assemble on the outer surface of desilicated zeolite by electrostatic interaction, and, by reducing the alkalinity, an amorphous mesolayer can be obtained [24]. The yield of HMZ can reach $100 \mathrm{wt}$ $\%$. Because only a small portion of the silica was dissolved under $0.2 \mathrm{M} \mathrm{NaOH}$, which could only support a thin shell, there is no obvious boundary between core and shell, and it is more appropriate to describe this process as surface reconstruction. In addition, intracrystalline hierarchical channels can be retained inside the bulk particles as indicated by the arrows in Figure 1c.

The textural properties of the three samples are listed in Table 1. The mesopores' specific surface area and pore volume of $\mathrm{HZ}$ increase to $109 \mathrm{~m}^{2} / \mathrm{g}$ and $0.14 \mathrm{~cm}^{3} / \mathrm{g}$, respectively. However, due to the partial destruction of microstructure, $\mathrm{S}_{\text {micro }}$ (micropore specific surface area) decreases and $\mathrm{S}_{\mathrm{BET}}$ (total specific surface area) is the same as that of PZ. The self-assembled composite sample maintains the same $\mathrm{S}_{\mathrm{BET}}, \mathrm{Vmicro}$ (micropore volume) and $\mathrm{V}_{\text {meso }}$ (mesopore volume) as $\mathrm{HZ}$, but $\mathrm{S}_{\text {meso }}$ (mesopore specific surface area) increases to $139 \mathrm{~m}^{2} / \mathrm{g}$, indicating the contribution of mesolayer.

Table 1. Textural properties of three samples.

\begin{tabular}{ccccccc}
\hline Sample & $\begin{array}{c}\mathbf{S}_{\text {BET }} \mathbf{a} / \mathbf{m}^{2} \\
\mathbf{g}^{-\mathbf{1}}\end{array}$ & $\begin{array}{c}\mathbf{S}_{\text {micro }} \mathbf{b} / \mathbf{m}^{\mathbf{2}} \\
\mathbf{g}^{-\mathbf{1}}\end{array}$ & $\begin{array}{c}\mathbf{S}_{\text {meso }} / \mathbf{m}^{2} \\
\mathbf{g}^{\mathbf{1}}\end{array}$ & $\begin{array}{c}\mathbf{V}_{\mathrm{T}} \mathbf{c} / \mathbf{c m}^{3} \\
\mathbf{g}^{-\mathbf{1}}\end{array}$ & $\begin{array}{c}\mathbf{V}_{\text {micro }} \mathbf{d} / \mathbf{c m}^{\mathbf{3}} \\
\mathbf{g}^{-\mathbf{1}}\end{array}$ & $\begin{array}{c}\mathbf{V}_{\text {meso }} \mathbf{c m}^{3} \\
\mathbf{g}^{\mathbf{- 1}}\end{array}$ \\
\hline PZ & 340 & 258 & 82 & 0.17 & 0.14 & 0.03 \\
HZ & 323 & 214 & 109 & 0.24 & 0.10 & 0.14 \\
HMZ & 355 & 216 & 139 & 0.24 & 0.11 & 0.13 \\
\hline
\end{tabular}

${ }^{\mathrm{a}}$ BET method. ${ }^{\mathrm{b}}$ t-plot method. ${ }^{\mathrm{c}}$ Calculated at a relative pressure $\mathrm{P} / \mathrm{P}_{0}$ of $0.99 .{ }^{\mathrm{d}}$ NLDFT method.

Combining the pore size distribution calculated by the NLDFT (Non-Local Density Functional Theory) method (Figure 2), it can be seen that HZ has a continuous distribution of mesopores, mainly centered on the 5-8 nm and $20 \mathrm{~nm}$ size ranges, corresponding to various types of hierarchical channels. These large pores $(>10 \mathrm{~nm})$ can be attributed to the channels with big openings and breakage slits. The HMZ sample also has no obvious single-peak distribution. However, unlike the hierarchical sample, the mesopores around $20 \mathrm{~nm}$ in size disappear, and more mesopores are distributed in the range of 3-9 $\mathrm{nm}$. Combined with the TEM results, it can be inferred that the open mesopores or macropores caused by desilication have been partially filled, and the amorphous mesoporous shell is coated outside. This may be due to the $\mathrm{pH}$-changing process in redeposit preparation, which makes CTAB micelles assemblies less stable than those from the Stöber method. 


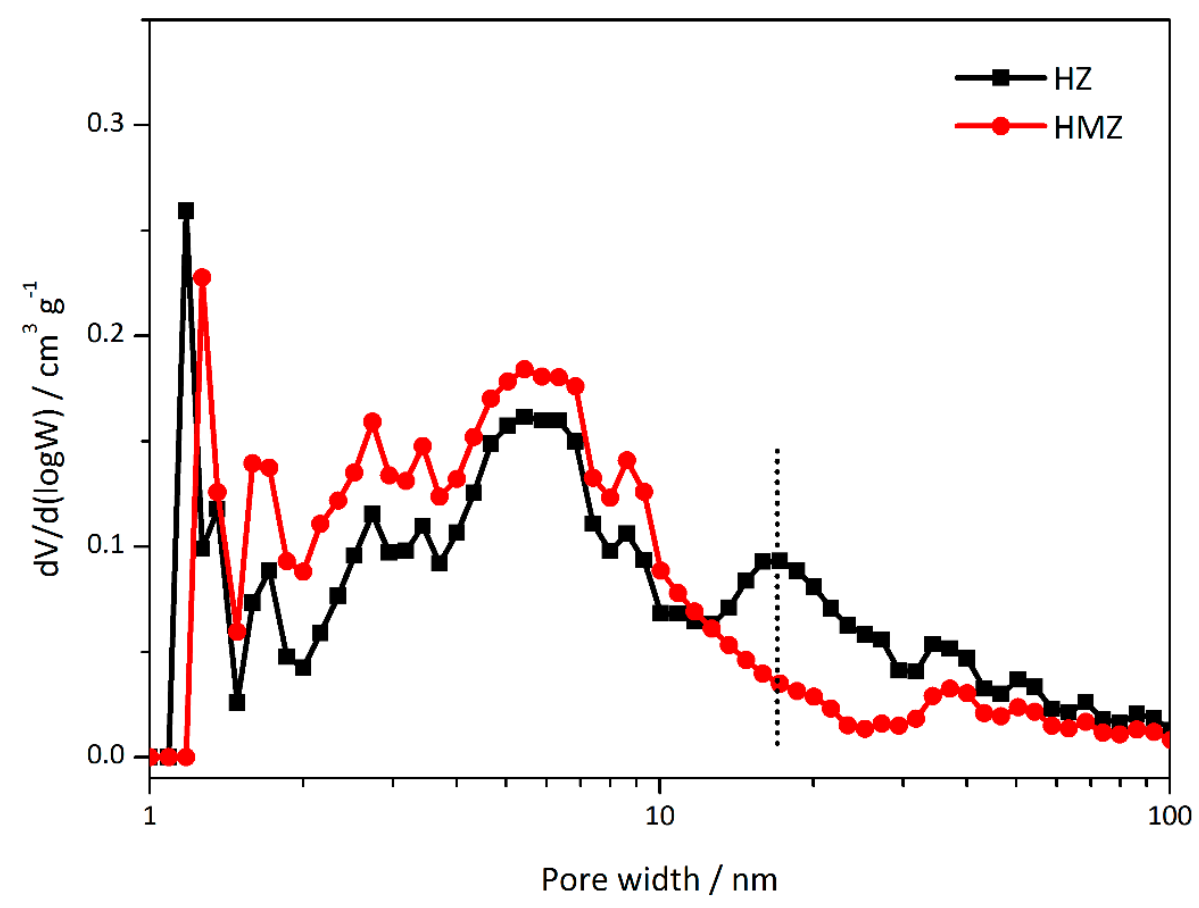

Figure 2. Pore size distribution by NLDFT method.

The acidic properties and surface $\mathrm{Si} / \mathrm{Al}$ ratio are listed in Table 2, in which the weak acid sites and strong acid sites correspond to the TCD peaks in $200{ }^{\circ} \mathrm{C}$ and $375-400{ }^{\circ} \mathrm{C}$, respectively. Alkaline treatment reduces the amount of Brønsted acid, so the HZ's strong acidity is further reduced to 0.1 $\mathrm{mmol} / \mathrm{g}$ [25]. HMZ maintains acidity very close to that of HZ. In addition, the change of $\mathrm{Si} / \mathrm{Al}$ ratio on the outside surface has also been analyzed by X-ray photoelectron spectroscopy (XPS). The Si-O-Si bond is more easily broken during the alkali treatment, leading to more loss of silica and a reduced $\mathrm{Si} / \mathrm{Al}$ ratio. X-ray photoelectrons have limited penetration, so the XPS method can only detect the Si/Al ratio of the mesoporous layer. It can be seen that the mesolayer of HMZ has some weak acidity with a $\mathrm{Si} / \mathrm{Al}$ ratio of 36 . This is because the partial dissolved alumina species have also been assembled by CTAB micelles to form an Al-MCM-41 type layer.

Table 2. Acidity properties and surface $\mathrm{Si} / \mathrm{Al}$ ratio of samples.

\begin{tabular}{ccccc}
\hline Sample & $\begin{array}{c}\text { Weak Acid } \\
\mathbf{a} / \mathbf{m m o l ~ g}^{\mathbf{- 1}}\end{array}$ & $\begin{array}{c}\text { Strong Acid } \\
\mathbf{a} / \mathbf{m m o l ~ g}^{\mathbf{- 1}}\end{array}$ & $\begin{array}{c}\text { Total Acid/mmol } \\
\mathbf{g}^{\mathbf{- 1}}\end{array}$ & Si/Al $^{\mathbf{b}}$ \\
\hline PZ & 0.29 & 0.22 & 0.51 & 23 \\
HZ & 0.34 & 0.10 & 0.44 & 17 \\
HMZ & 0.30 & 0.11 & 0.41 & 36 \\
\hline
\end{tabular}

${ }^{a}$ Calculated from $\mathrm{NH}_{3}$-TPD curves. ${ }^{\mathrm{b}}$ X-ray photoelectron spectroscopy (XPS) results.

Based on the comprehensive characterization results, it can be concluded that by the combination of the conventional hierarchical zeolite preparation and the redeposition process, a new type of composite micro-mesostructure can be constructed with a weight yield of nearly $100 \%$, which makes up for the raw material loss caused by desilication. Furthermore, the composite sample has a relatively unordered and weak acidic mesoporous layer with a large pore size, while retaining the intracrystalline hierarchical pores inside the bulk phase.

\subsection{Pyrolysis of Raw Materials}

First, the pyrolysis product distributions of the three raw materials were listed in Figure 3. Among them, the phenolics include phenol and its derivatives (denoted as O1P), guaiacol and its derivatives 
$(\mathrm{O} 2 \mathrm{P})$, and few syringol-type monomers (O3P). Catechol and its alkyl products are referred as catechols. Non-phenolic oxygenates are referred as Oxy. In addition, there are some aliphatic hydrocarbons (HCs), organic-sulfur compounds (OSC) and nitrogen-containing compounds (NC). NC is further divided into heteromonocyclics (MNC) and oxygen-containing NC (ONC). It could be seen that the pyrolysis yield of KL was very low. Combined with Figure 4c, most products were phenolics, accounting for more than 50 area \% of the total oxygenated products' peak area, with more O2P than O1P. High content products included acetic acid, vanillin and dimethyl disulfide, derived from the introduction of sulfur during the preparation of KL [26]. The pyrolysis yield of PL increased significantly, and the total peak area was about 8.5 times that of $\mathrm{KL}$, containing a small amount of aromatics. Most of the products were phenolics with a content of 70 area \%, of which there were more O1P. In addition, there were more aldehydes, ketones, NC and other oxygenates, mostly containing aromatic rings. Poplar also had a high pyrolysis yield, but there were only 20 area \% of phenolics with higher O2P content, and more small molecule products. The products were very complicated, and typical components were acetic acid, furan, acetic anhydride, hydroxyacetone, cyclohexanone, and some monomer fragments of $\beta-\mathrm{O}-4$ bonds.

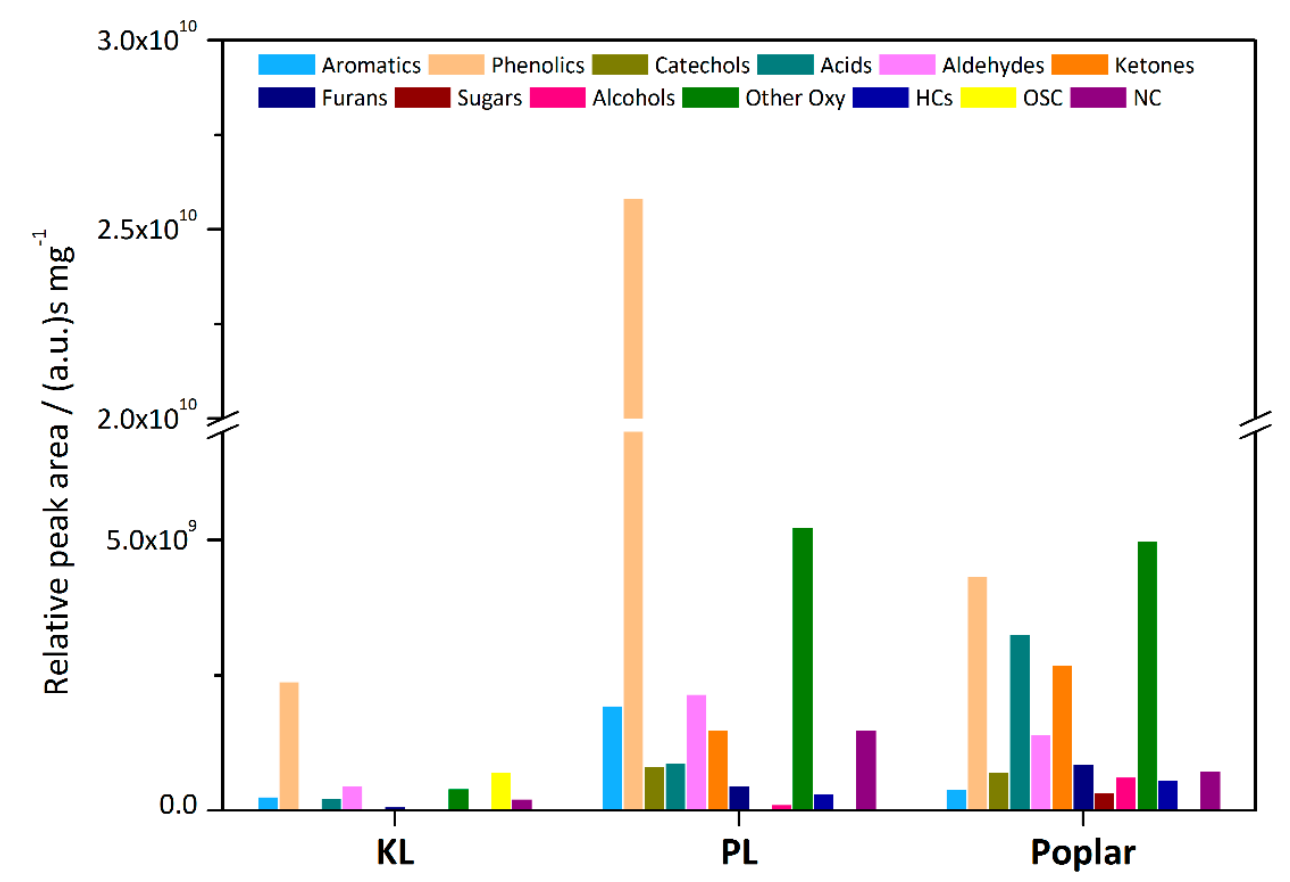

Figure 3. Pyrolysis product distribution of Kraft lignin (KL), pyrolytic lignin (PL) and poplar sawdust. 


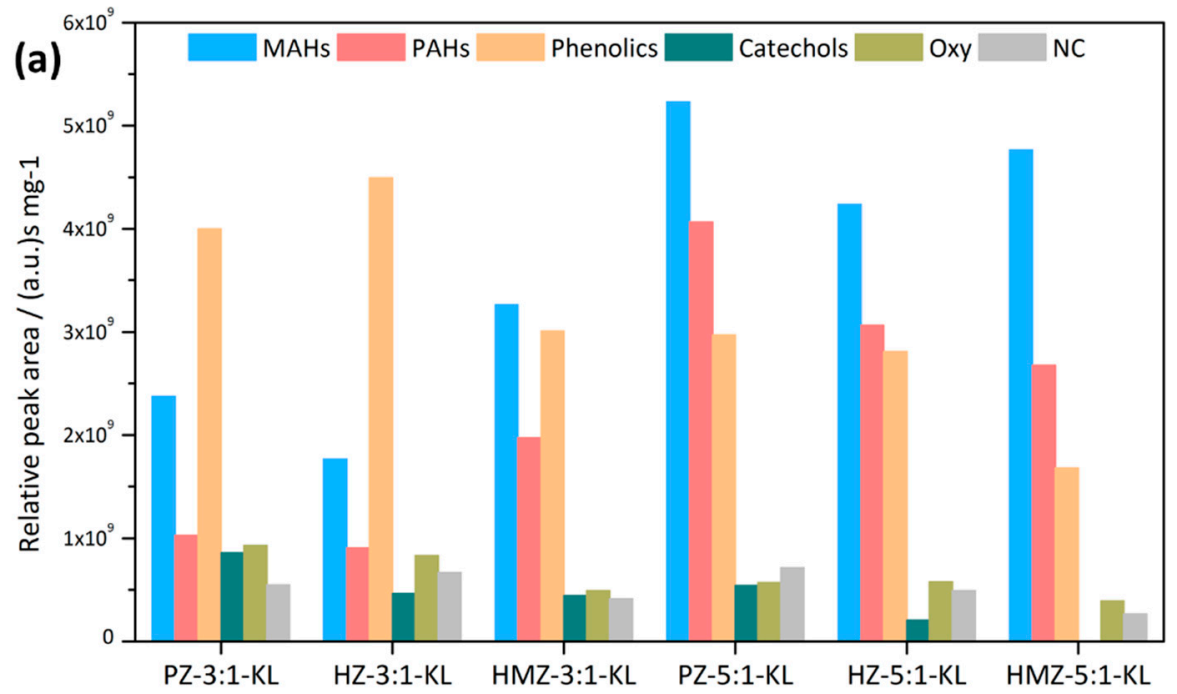

(b)

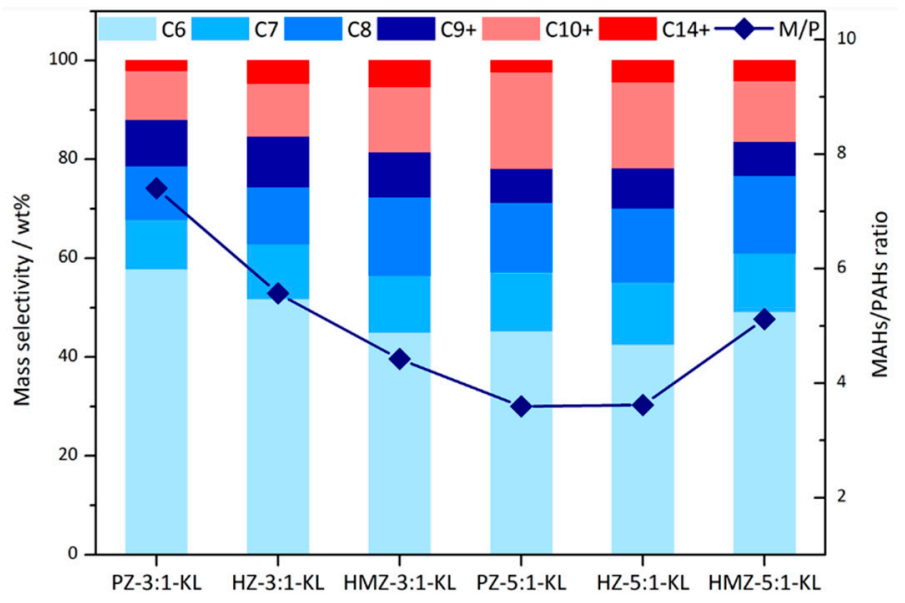

(c)

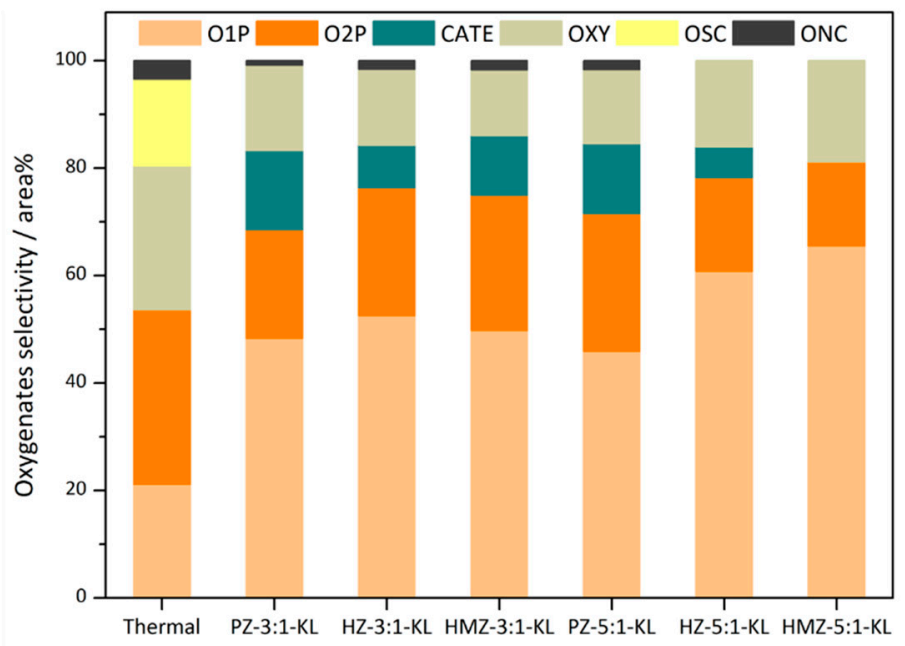

Figure 4. Product distribution of KL catalytic fast pyrolysis (CFP). (a) Overall distribution based on GC-MS peak area; (b) mass distribution of aromatics; (c) relative selectivity of oxygenated products.

According to the SEM results shown in Figure S1, the micro-morphology and dispersion of raw materials with mixed catalysts had been checked, and the particle size was estimated by measuring 20 catalyst and lignin particles. Based on the characterization results from previous studies, the $\mathrm{C}-\mathrm{O}-\mathrm{C}$ linkages in $\mathrm{KL}$ and $\mathrm{PL}$, including $\beta-\mathrm{O}-4$ and $\alpha-\mathrm{O}-4$, had been basically destroyed, leaving only the $\mathrm{C}-\mathrm{C}$ linkages $[27,28]$. KL had a high average molecular weight $(\mathrm{Mw}=3930)$ and large particle sizes, which could reach $5 \mu \mathrm{m}$. Therefore, a large number of cross-linked structures would undergo further 
polycondensation and coking, resulting in low liquid yield and more char. PL was product of lignin pyrolysis fragments, with a much smaller average molecular weight $(\mathrm{Mw}=998)$ and particle sizes of around $3 \mu \mathrm{m}$. Therefore, during the pyrolysis, the faster heat transmission and smaller oligomers could produce more volatiles instead of char. Typically, the poplar had a Klason lignin content of about $20 \mathrm{wt} \%$, and cellulose and hemicellulose content of $45 \mathrm{wt} \%$ and $21 \mathrm{wt} \%$, respectively [29]. Therefore, the concentration of heavy components in the pyrolysis vapor was lower than that of PL.

\subsection{CFP Performance of $K L$}

A C:L ratio of 5 is a commonly used ratio in CFP. In addition, in order to better reveal the samples' conversion ability on heavy phenols, a low $\mathrm{C} / \mathrm{L}$ ratio of 3:1 was also used to compare the conditions of relatively sufficient and insufficient catalyst. It could be seen in Figure 4a that at a mixing ratio of 3:1, KL could only be partially deoxygenated. PZ could only produce a small amount of aromatics and there remained many phenolics, catechols and oxygenate products. Further, hierarchical HZ had the worst performance, with lower phenolics conversion and aromatic products. The HMZ sample had a significantly better deoxygenation. Compared with HZ, phenolics had decreased by $1 / 3$, MAHs and PAHs had doubled, and oxygenates had further reduced. At a mixing ratio of 5:1, the catalytic effect was significantly improved, indicating that KL CFP was sensitive to the amount of catalyst. PZ had the highest MAHs product, which was more than twice that of the 3:1 mixing ratio, while PAHs increased by 3 times. HZ still had the least MAHs, and had a similar increase proportion to that of PZ. HMZ continued to have a high aromatics yield and had the lowest amount of PAHs and oxygenated products, which showed the best catalytic performance.

Combining the mass distribution of aromatics in Figure $4 \mathrm{~b}$, it could be seen that the most abundant products were benzene, accounting for about $50 \mathrm{wt} \%$. Under a C/L ratio of 3, from PZ to HMZ, the alkylated products gradually increased, especially $\mathrm{C} 8$ and $\mathrm{C} 10+$, and the $\mathrm{MAHs} / \mathrm{PAHs}$ ratio $(\mathrm{M} / \mathrm{P})$ also decreased from 7.4 to 4.4. For a C/L ratio of 5, PAHs of both PZ and HZ increased to more than 20 wt $\%$, accompanied by decreased $\mathrm{C} 9+$ product and benzene, and the corresponding $\mathrm{M} / \mathrm{P}$ dropped to about 3.6. Meanwhile, HMZ maintained the degree of alkylation and the M/P ration increased slightly to 5.1. It can be concluded that the product alkylation of PZ and HZ was greatly affected by the adequacy of the catalysts. The selectivity of oxygenated products was expressed by the relative peak area percentage in Figure 4c. CFP could completely convert OSC and reduce the selectivity of Oxy. In addition, more O2P had been converted, for the selectivity of O1P was higher. There was only a small catechol content, because catechols were byproducts of phenols via pyrolysis. At a mixing ratio of 5:1, two mesoporous samples' selectivity of O1P increased from 50 area \% to more than 60 area $\%$, and the selectivity of $\mathrm{O} 2 \mathrm{P}$ reduced to less than 20 area \%. The catechols product of HMZ had completely disappeared.

It could be concluded that although KL had a low pyrolysis yield, its deoxygenation was difficult. Under the optimal conditions, the selectivity of O2P was still 16 area \% (in oxygen-containing products). Hierarchical HZ slightly improved demethoxylation, but its intracrystalline mesopores had not achieved the expected optimized catalytic performance, and had low shape-selectivity to PAHs products. The HMZ sample with an unordered mesolayer had the highest deoxygenation and stably maintained a high selectivity and yield for MAHs.

\subsection{CFP Performance of $P L$}

As shown in Figure 5, the total peak area of corresponding product of PL CFP was nearly four times that of KL CFP. The conversions of the three catalysts on phenolics were all higher, with more aromatics generated. The difference in product between different catalysts and $\mathrm{C} / \mathrm{L}$ ratios was also much smaller than in KL CFP. At a C/L ratio of 3, HZ had most MAHs and reduced PAHs, which reflects the benefit of mesopores on the increased active sites. HMZ's oxygenates and aromatics were both decreased, which may correspond to more char formation. At C/L of 5, the presence of more catalysts didn't improve PZ's product distribution, corresponding to a saturated condition. The MAHs 
of mesoporous samples had increased by $20 \%-35 \%$. The phenolics and catechols of HZ were also reduced by one-third and one-half, respectively, showing better conversion of oxygenates than that of HMZ.

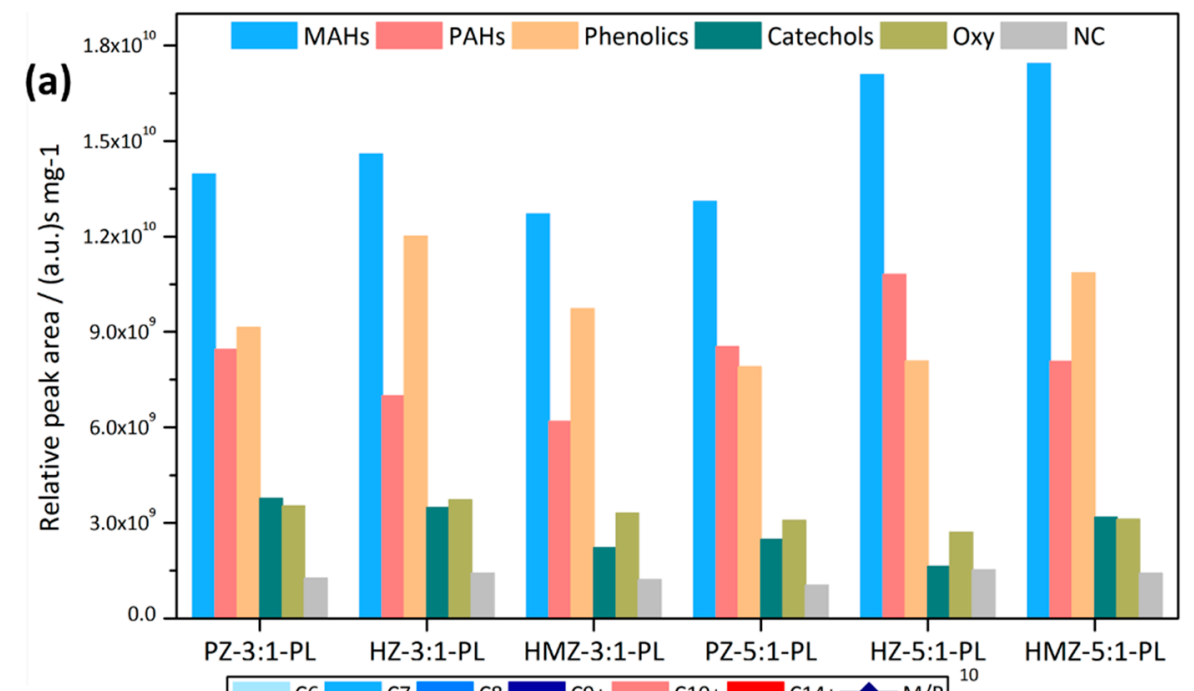

(b)

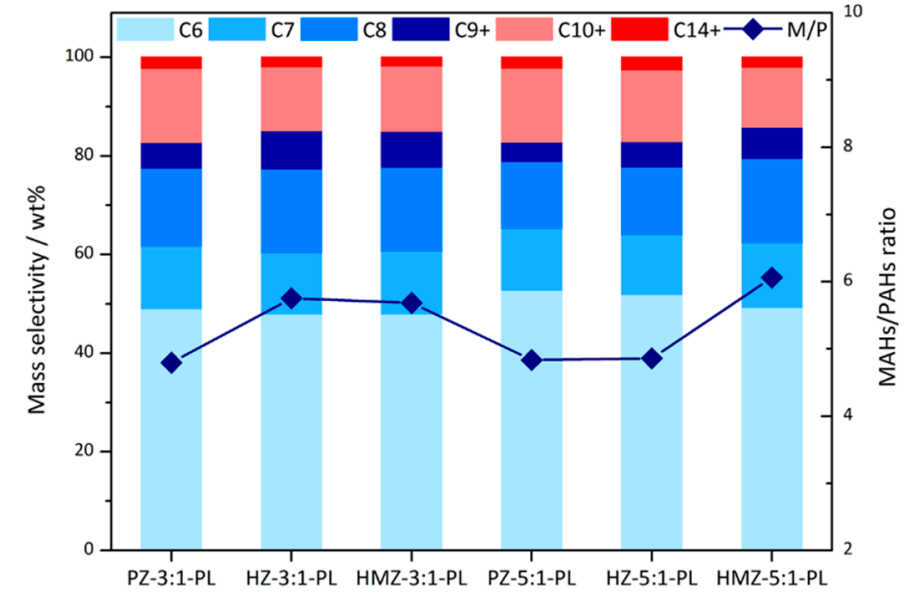

(c)

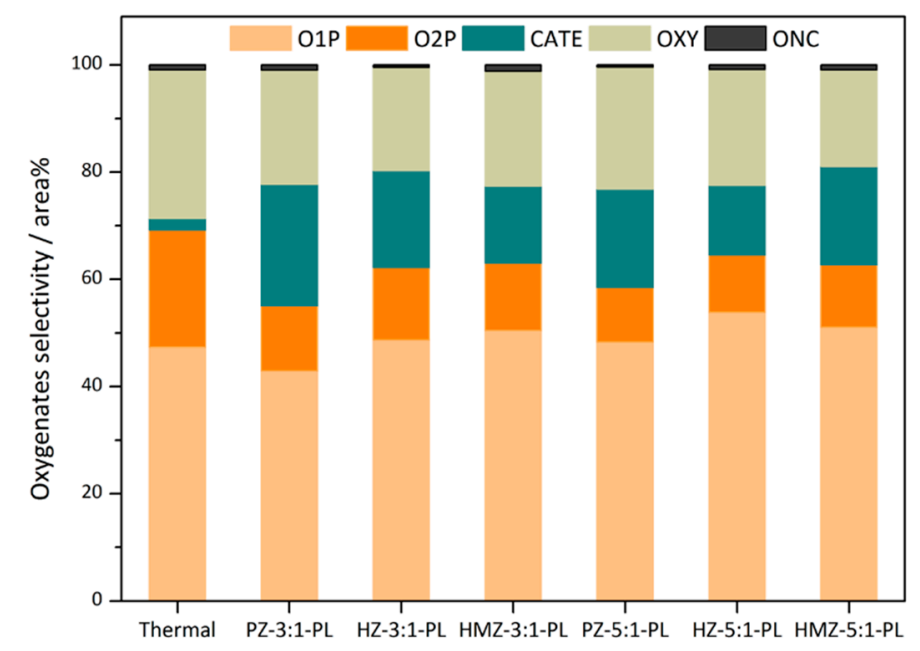

Figure 5. Product distribution of PL CFP. (a) Overall distribution based on GC-MS peak area; (b) mass distribution of aromatics; (c) relative selectivity of oxygenated products.

It could be seen in Figure 5 that the catechols content was higher, due to the higher primary phenolics which caused more secondary reactions. PZ had fewer C 8 and $\mathrm{C} 9+$ products, and the selectivity of catechol products reached 20 area $\%$. This corresponded to the fact that its deoxygenation 
in the microporous channels was selective for alkylbenzenes, and many phenolic reactants that cannot diffuse into the micropores would undergo polycondensation on the outer surface to generate PAHs, catechol, or carbon deposits, resulting in $\mathrm{M} / \mathrm{P}$ ratios of less than 5 and less phenolics. HZ and HMZ had O1P selectivity over 50 area \%, but Oxy was still hard to convert. HZ had over-alkylated products at $\mathrm{C} / \mathrm{L}$ of 5 , while HMZ maintained the inhibition to PAHs, which was consistent with KL's CFP. The catechols' selectivity and amount of phenolics of HMZ were higher at 5:1. This result may be because the weak acid sites on the mesolayer could facilitate some phenolic oligomers that could not be recognized by GC-MS to further crack into monophenols.

It could be concluded that the conventional ZSM-5 catalyst could already achieve considerable PL conversion. HZ was more suitable for PL CFP, for having higher MAHs products and fewer oxygenates. HMZ did not have the big advantages over HZ, but still maintained optimal MAHs selectivity. Interestingly, the influence of the adequacy of the catalysts on the products distribution was much smaller. This may be because the massive reactants had reached a near-saturated concentration inside the catalyst channel, and further increasing phenolics could only led to more non-catalytic pyrolysis and char.

The aromatics and phenolics mass yield of KL and PL CFP were listed in Figure 6. KL had a much lower yield than PL. The aromatics yields of $\mathrm{HZ}$ and $\mathrm{HMZ}$ increased to $2.1 \mathrm{wt} \%$ and $3.3 \mathrm{wt} \%$, and the phenolics yields decreased to $1.1 \mathrm{wt} \%$ and $0.6 \mathrm{wt} \%$, respectively. It is worth noting that the phenolics yield of KL CFP was higher than that of non-catalytic pyrolysis. Additionally, in the case of PL CFP, phenolics decreased significantly ( $8 \mathrm{wt} \%$ to $3 \mathrm{wt} \%$ ) with the aromatics production enhanced $(0.5 \mathrm{wt} \%$ to $10 \mathrm{wt} \%)$. It was determined that most of the aromatics in PL CFP were the products of direct deoxygenation of phenols, while KL CFP had a more complicated situation. The large molecular weight of KL led to a higher degree of polymerization of pyrolysis products, and the surface acid sites of zeolites could absorb a part of the primary pyrolysis fragments for secondary cracking, promoting further catalytic depolymerization of KL. In the case of PL CFP, PZ had aromatics and phenolics yields of about $10 \mathrm{wt} \%$ and $2.7 \mathrm{wt} \%$, respectively. At a C/L ratio of $5, \mathrm{HZ}$ had the highest aromatics yield of $12.7 \mathrm{wt} \%$ with a phenolics yield of $2.6 \mathrm{wt} \%$, and that of $\mathrm{HMZ}$ were $11.4 \mathrm{wt} \%$ and $3.5 \mathrm{wt} \%$, respectively.

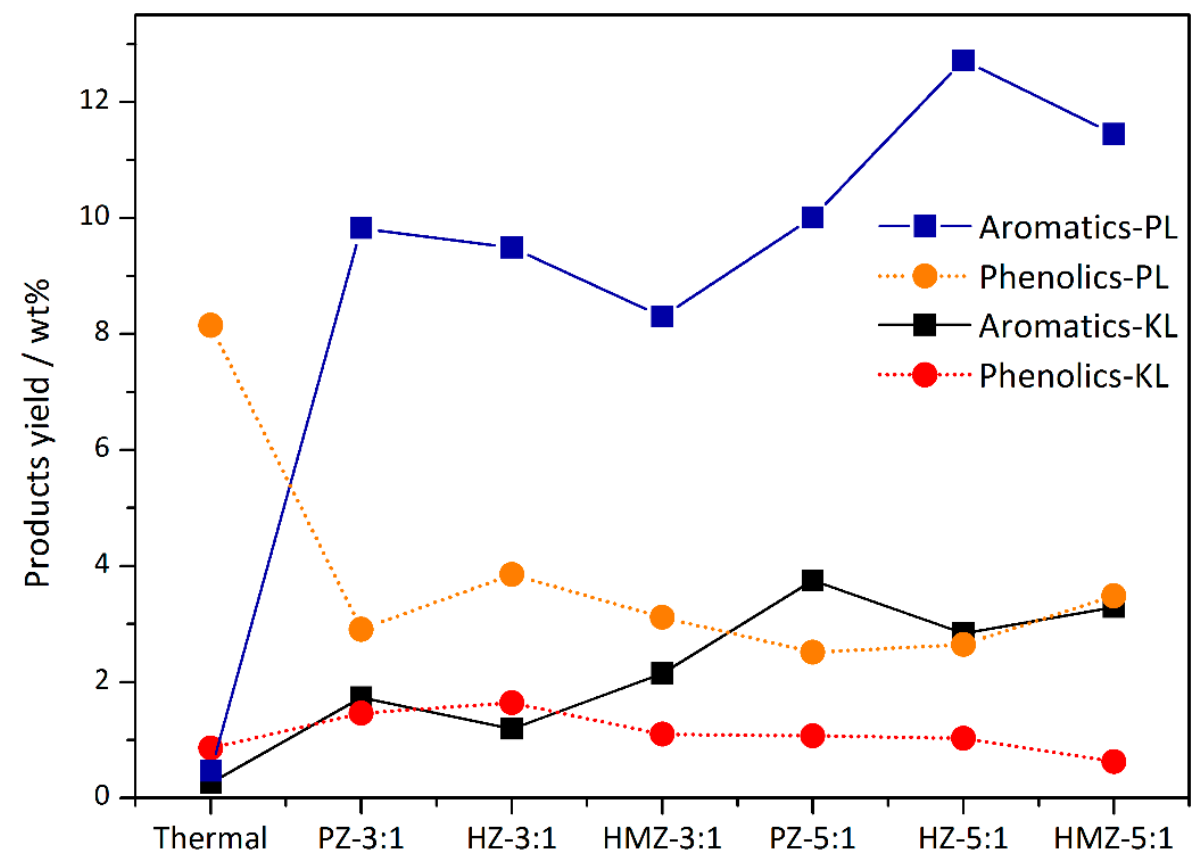

Figure 6. Target products yield of KL and PL CFP.

By summarizing the CFP results, it could be seen that the CFP of KL corresponded to the reaction condition of lower reactants concentration with high oxygen content, and the CFP of PL corresponded 
to the condition of higher concentration. These two mesoporous samples had different applicability: HZ had certain competitiveness in CFP of high-quantity phenolics; whereas HMZ was more suitable for conversion at lower phenolics concentrations.

For KL CFP, the reactants could be completely converted after a short distance of diffusion in the catalyst channels, so most of the reactions actually occurred on the surface area only. For PL CFP, the phenolic concentration was much higher, corresponding to the need for a deeper diffusion distance. Combined with the structural characteristics of the catalyst, the major factor in KL conversion was the catalyst's exterior structure, and the internal pore structure had a great effect on PL conversion. In contrast to the configurational diffusion in micropore channels, the diffusion mechanism in mesopores needed to consider the joint contribution of configurational diffusion and Knudsen diffusion [30]. The hierarchical sample had funnel-shaped openings on the surface, with pore size as large as $20 \mathrm{~nm}$ or more. At this size, the diffusion of monomers should also take into account the effects of molecular diffusion. At low concentrations, these large mesopores caused excessive diffusion rates for reactants and products, and possess no shape-selectivity. Therefore, it was difficult for oxygenates to undergo a sufficient deoxygenation reaction, and more intermediates could grow in an uncontrolled fashion to form PAHs. The coated amorphous mesolayer of HMZ had certain weak acidity, and could perform an additional pre-reaction, removing some oxygen and unstable small molecules. In addition, the mesoporous layer was uniformly distributed on the entire surface, which had a stronger capture capability, and could increase the quantity of internal reactants. By this means the conversion on phenolics of KL CFP increased effectively. Combined with the pore size distribution obtained by the NLDFT method, it could be seen that HMZ had a smaller average equivalent mesopore size relative to HZ, due to its reduced $20 \mathrm{~nm}$ mesopores. Therefore, there should be less molecular diffusion taking place inside HMZ. Consequently, the shape-selectivity of light aromatics was more obvious. Due to the smaller internal mesopores and the elimination of excessive large open channels, it could be referred to that HMZ possessed a stable core during CFP reaction. Furthermore, in the case of high-concentration phenolic reactants of PL CFP, the internal structure played a major role, which might explain why HMZ could still maintain an effective inhibitory effect on PAHs. However, the smaller equivalent mesopores also made the diffusion rate of the reactants slower than that of HZ. Therefore, some oxygen-containing components could not diffuse into the strong acidic core for deoxygenation, resulting in lower phenolics conversion.

\subsection{CFP Performance of Poplar}

In order to further explore the effect of composite samples on different lignin contents, the CFP of poplar was also analyzed at the optimal 5:1 mixing ratio, as a representative of full-component lignocellulosic biomass. In Figure 7a, although the total peak area was also high, the peak area of phenolics was only twice that of KL due to a greater number of small molecular components. The lower lignin content made it easier to obtain high conversion. It could be seen that most of the products were aromatics, with a small amount of oxygenated products remaining, having selectivity of 14.5-19 area $\%$. PZ's PAHs had a higher peak area than that of MAHs, and the corresponding M/P in Figure 7b was only 2.8. The mesoporous samples still had significant performance improvements: MAHs increased with higher $\mathrm{C} 8$ and $\mathrm{C} 9+$ selectivity, corresponding to $\mathrm{M} / \mathrm{P}$ ratios of 5.1 and 4.9. The stronger alkylation effect could be contributed to by the larger mesopore volume. The product distributions of the two meso-samples were similar, but HMZ had more MAHs and oxygenates, with selectivity of phenolics increased from 20 area \% of non-catalytic to 40 area \%. Most of the small molecules had been completely converted, and only acetic acid remained. Most of the Oxy were macromolecules, including dimethoxy hydroxybenzaldehyde, benzofurans, naphthols, etc., which belonged to by-products of catalytic cracking larger molecules. 

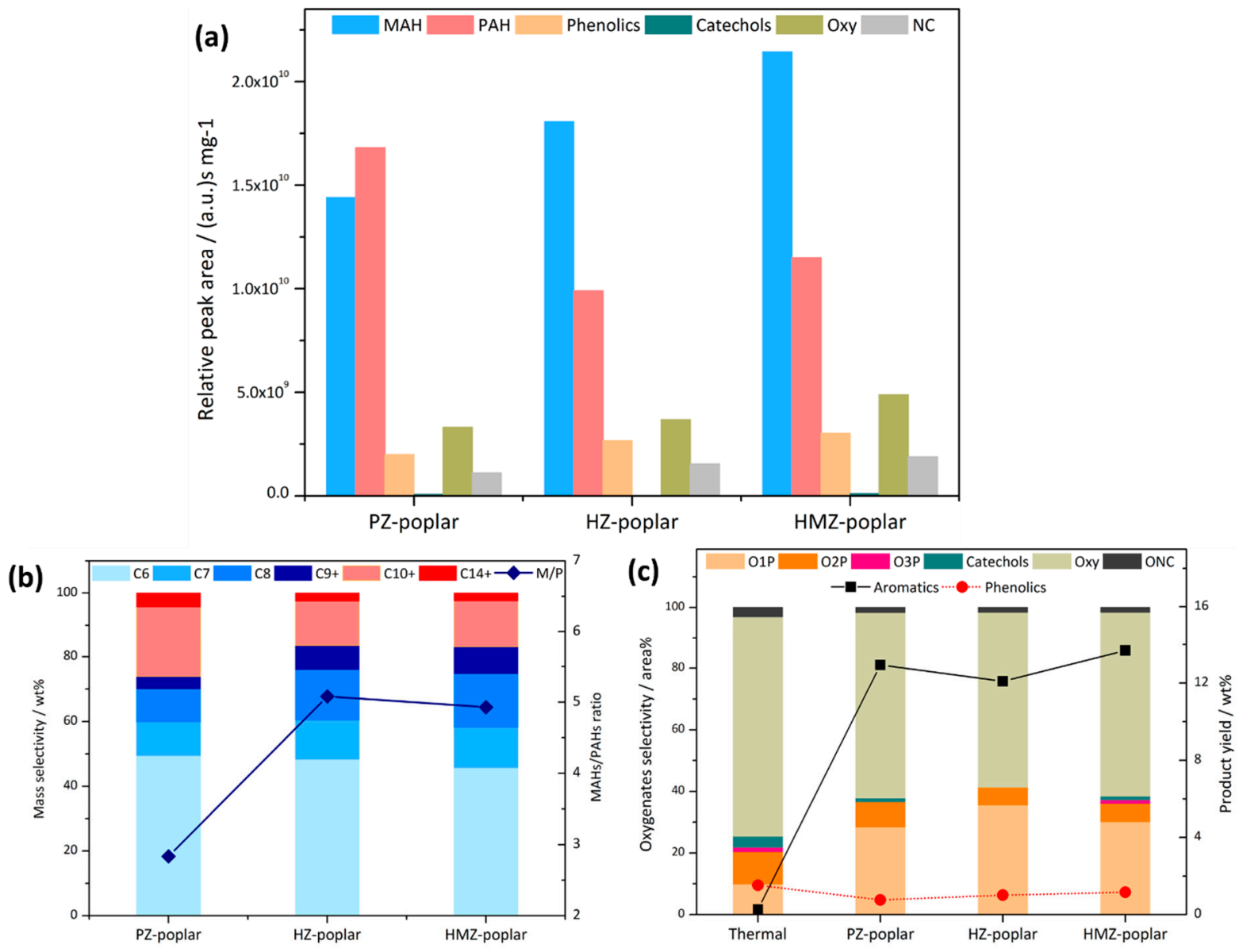

Figure 7. Product distribution of poplar sawdust. (a) Overall distribution based on GC-MS peak area; (b) mass distribution of aromatics; (c) relative selectivity of oxygenated products and yield of aromatics and phenolics.

As shown in Figure 7c, the aromatics yield of poplar CFP could reach 12.1-13.7 wt \%, and this increase was far greater than the reduction in phenols. Therefore, in full-component biomass CFP, the path of aromatics generation was very different from the pyrolysis of lignin. Except for the direct demethoxylation and dehydroxylation of phenols, large amounts of the aromatics were generated by the secondary reaction of small molecular components. Reactants first underwent decarboxylation, decarbonylation and dehydration to produce light olefins, and then through oligomerization and aromatization, along with Diels-Aldor reaction, generated light aromatics products [31]. According to the hydrocarbon pool mechanism, in the case of poplar CFP, the major intermediates were polymethylbenzene carbocation. Further, in the case of pure lignin CFP, there was a phenolic pool rather than hydrocarbon pool, of which the intermediates were larger [17,32]. This necessitated higher requirements for the mass transfer and diffusion capacity of the catalyst. Therefore, the effect of topology of mesostructure on poplar CFP was much smaller. The increased yield using HMZ may be due to the fact that its mesolayer could enrich small molecules. It is worth mentioning that by using two meso-zeolites as catalysts, a yield of aromatics close to that of PL CFP could be achieved.

Combining the CFP results of two lignin residues and poplar sawdust, conclusions can be made about the optimized quality of aromatic products using HMZ and the feasibility of high-value utilization of PL by producing aromatics through the CFP technique. Further research should focus on the consecutive cycle performance of mesoporous catalysts and the improvement of effective fuel or chemical components in CFP products by engineering the composite pore structures, or metal loading. Considering the similarity of conversion routes, the application of composite zeolites in ex-situ CFP is also worthy of systematic investigation. The reaction conditions of ex-situ CFP are 
closer to the case of low C/L. Thus, according to the conclusions in this manuscript, the catalyst needs to maintain a certain internal mesoporosity. By increasing the catalyst preparation yield, HMZ can reduce certain costs of making hierarchical zeolites, which may be conducive to raising the prospects of subsequent scaled-up experiments with continuous feed. Considering the product yield and selectivity, using PL and lignocellulosic biomass as raw materials for scaled-up experiments is highly feasible and economical.

\section{Materials and Methods}

\subsection{Raw Materials}

ZSM-5 zeolite ( $\mathrm{Si} / \mathrm{Al}=25$, denoted as PZ) was purchased from Nankai University Catalyst Factory (Tianjin, China). Kraft lignin was purchased from Sigma-Aldrich (St. Louis, MO, USA). Pyrolytic lignin was obtained from heavy fractions of rice straw pyrolysis bio-oils by the precipitation method, which is listed in SI and is documented in a previous work on the characterization of pyrolytic lignin [28]. All biomass materials were ground with a ball mill and sieved to over 150 meshes.

\subsection{Preparation Method of Mesoporous Zeolites}

\subsubsection{Hierarchical ZSM-5}

Hierarchical samples were prepared by classic desilication methods [33]. Specifically, ZSM-5 was added to $0.2 \mathrm{M} \mathrm{NaOH}$ solutions and reacted at $343 \mathrm{~K}$ for half an hour, and was then put into ice-water bath. Ion exchange was carried out using a $1 \mathrm{M} \mathrm{NH}_{4} \mathrm{Cl}$ solution at $353 \mathrm{~K}$ and calcined at 823 K. Prepared samples were marked as HZ.

\subsubsection{Mesoporous Composite ZSM-5}

First $2 \mathrm{~g}$ of ZSM-5 was processed with the same desilication as above. Then a water/ethanol solution of hexadecyltrimethylammonium bromide $(\mathrm{CTAB})$ was slowly added to above mixture to achieve a mass composition: 1CTAB:2ZSM-5:0.48NaOH: $85 \mathrm{H}_{2} \mathrm{O}: 50 \mathrm{EtOH}$. The slurry was stirred at 308 $\mathrm{K}$ for $1 \mathrm{~h}$, and the $\mathrm{pH}$ was neutralized to about 7 with $1 \mathrm{M} \mathrm{HCl}$, followed by addition of $1 \mathrm{ml}$ ammonia. Subsequently, the solution was continuously stirred at $308 \mathrm{~K}$ for $6 \mathrm{~h}$. The precipitate was ion-exchanged with $\mathrm{NH}_{4} \mathrm{Cl}$ and finally calcined at $823 \mathrm{~K}$ for $5 \mathrm{~h}$, and the obtained sample was denoted as HMZ. All the reagents used in catalysts' preparation were purchased from Sinopharm (Shanghai, China).

\subsection{Catalytic Fast Pyrolysis of Lignin and Biomass}

Catalytic pyrolysis experiments were performed on a Py-GCMS (pyrolyzer-gas chromatography mass spectrometry) hyphenated instrument (Frontier EGA/PY3030D, Koriyama, Fukushima, Japan). Before each reaction, the catalyst and lignin or biomass were ground in a mortar for 10 minutes by mixing ratios of $3: 1$ or 5:1, until uniformly mixed. The feedstock was filled into a micro crucible, and a little quartz wool was placed above to keep it fixed. The amount of each feedstock was $2 \mathrm{mg}$ or $3 \mathrm{mg}$ by each mixing ratio to keep the loading of lignin at $0.5 \mathrm{mg}$, so that the quantity of primary pyrolysis products was constant. The reaction temperature was $873 \mathrm{~K}$ and the residence time was $30 \mathrm{~s}$. The liquid product vapor was then directly entered into GC-MS (Thermo Scientific Trace GC Ultra and DSQ II, Waltham, MA, USA) for analysis. Each condition was repeated three times to eliminate systematic errors. The yields of the main products (aromatics, phenolics, and catechols) were quantified using the external standard method. A detailed experiment procedure and the specific product classification are listed in Table S1 and SI.

\subsection{Characterization}

The micro-morphology of mixed catalyst and lignin was observed by scanning electron microscopy (SEM) with ZEISS Gemini300 (Oberkochen, Germany) at an acceleration voltage of 
$15 \mathrm{kV}$. The mesostructure morphology of two mesopore samples was obtained by transmission electron microscopy (TEM) with FEI Talos F200S (Waltham, MA, USA) at $200 \mathrm{kV}$. The 77K nitrogen isotherm test was performed using a Micromeritics 3Flex gas adsorption analyzer (Norcross, GA, USA). Before testing, samples were degassed at $423 \mathrm{~K}$ for 4 hours to remove all adsorbed moisture. The pore size distribution was obtained by using the NLDFT method. Samples' acidic properties were obtained by temperature-programmed desorption of ammonia $\left(\mathrm{NH}_{3}-\mathrm{TPD}\right)$ on a Micromeritics AutoChem II 2920 (Norcross, GA, USA). The detailed test procedure is provided in the SI. The Si/Al ratio of particle surfaces was calculated by X-ray photoelectron spectroscopy (XPS) performed on an ESCALAB 250Xi (Waltham, MA, USA), using a focused $\mathrm{X}$-ray source $(\mathrm{Al} \mathrm{K} \alpha, \mathrm{hv}=1486.6 \mathrm{eV})$.

\section{Conclusions}

A novel micro-mesoporous composite ZSM- 5 with a weak acidic mesolayer was prepared by a redeposition method under mild conditions. The sample possessed excellent performance in both KL and PL CFP, showing a capability for suppressing the PAHs formation. This improved performance could be attributed to the combined effect of a mesoporous layer and a hierarchical core. The outer mesolayer could play the role of product pre-cracking, enriching molecules and promoting diffusion, while the mesoporous core retained certain shape-selectivity. These analyses provided suitable application scenarios for hierarchical mesopores and composite mesopores in the conversion of heavy components.

Supplementary Materials: The following are available online at http://www.mdpi.com/2073-4344/10/4/378/s1, Figure S1: SEM images of HZ sample mixed with raw materials. (a) KL; (b) PL; (c) poplar. Table S1: Major identified compounds classification ( $>0.1 \%$, relative peak area) by GC/MS. Table S2: Compounds used for GC/MS calibration. Table S3. Detailed product distribution by relative peak area of repeatability test of raw materials fast pyrolysis. Table S4. Detailed product distribution by relative peak area of repeatability test of KL CFP. Table S5. Detailed product distribution by relative peak area of repeatability test of PL CFP. Table S6. Detailed product distribution by relative peak area of repeatability test of poplar CFP.

Author Contributions: Conceptualization, W.W. and S.L.; methodology, Z.L.; experiment, W.W., S.X. and H.S.; data curation, H.S.; writing-Original draft preparation, W.W.; writing-Review and editing, S.X. and S.L.; visualization, W.W. and S.L.; project administration and funding acquisition, Z.L. All authors have read and agreed to the published version of the manuscript.

Funding: This work was supported by the National Key Technologies R\&D Program of China [No. 2018YFB1501405].

Conflicts of Interest: The authors declare no conflict of interest.

\section{References}

1. Kunkes, E.L.; Simonetti, D.A.; West, R.M.; Serrano-Ruiz, J.C.; Gärtner, C.A.; Dumesic, J.A. Catalytic conversion of biomass to monofunctional hydrocarbons and targeted liquid-fuel classes. Science 2008, 322, 417-421. [CrossRef]

2. Serrano-Ruiz, J.C.; Dumesic, J.A. Catalytic routes for the conversion of biomass into liquid hydrocarbon transportation fuels. Energy Environ. Sci. 2011, 4, 83-99. [CrossRef]

3. Xiu, S.; Shahbazi, A. Bio-oil production and upgrading research: A review. Renew. Sustain. Energy Rev. 2012, 16, 4406-4414. [CrossRef]

4. Fermoso, J.; Pizarro, P.; Coronado, J.M.; Serrano, D.P. Advanced biofuels production by upgrading of pyrolysis bio-oil. Wiley Interdiscip. Rev. Energy Environ. 2017, 6, 1-18. [CrossRef]

5. Wang, M.; Dewil, R.; Maniatis, K.; Wheeldon, J.; Tan, T.; Baeyens, J.; Fang, Y. Biomass-derived aviation fuels: Challenges and perspective. Prog. Energy Combust. Sci. 2019, 74, 31-49. [CrossRef]

6. Sun, Z.; Fridrich, B.; De Santi, A.; Elangovan, S.; Barta, K. Bright Side of Lignin Depolymerization: Toward New Platform Chemicals. Chem. Rev. 2018, 118, 614-678. [CrossRef] [PubMed]

7. Zakzeski, J.; Bruijnincx, P.C.A.; Jongerius, A.L.; Weckhuysen, B.M. The Catalytic Valorization of Lignin for the Production of Renewable Chemicals. Chem. Rev. 2010, 110, 3552-3599. [CrossRef] [PubMed] 
8. McClelland, D.J.; Galebach, P.H.; Motagamwala, A.H.; Wittrig, A.M.; Karlen, S.D.; Buchanan, J.S.; Dumesic, J.A.; Huber, G.W. Supercritical methanol depolymerization and hydrodeoxygenation of lignin and biomass over reduced copper porous metal oxides. Green Chem. 2019, 21, 2988-3005. [CrossRef]

9. Fan, L.; Zhang, Y.; Liu, S.; Zhou, N.; Chen, P.; Cheng, Y.; Addy, M.; Lu, Q.; Omar, M.M.; Liu, Y.; et al. Bio-oil from fast pyrolysis of lignin: Effects of process and upgrading parameters Bio-oil from fast pyrolysis of lignin: Effects of process and upgrading parameters. Bioresour. Technol. 2017, 241, 1118-1126. [CrossRef]

10. Jensen, P.A.; Le, D.M.; Zhou, G.; Jensen, A.D.; Knudsen, N.O. Direct upgrading of fast pyrolysis lignin vapor over the HZSM-5 catalyst. Green Chem. 2015, 18, 1965-1975.

11. Iisa, K.; Robichaud, D.J.; Watson, M.J.; ten Dam, J.; Dutta, A.; Mukarakate, C.; Kim, S.; Nimlos, M.R.; Baldwin, R.M. Improving biomass pyrolysis economics by integrating vapor and liquid phase upgrading. Green Chem. 2018, 20, 567-582. [CrossRef]

12. Rezaei, P.S.; Shafaghat, H.; Daud, W.-W. Production of green aromatics and olefins by catalytic cracking of oxygenate compounds derived from biomass pyrolysis: A review. Appl. Catal. A Gen. 2014, 469, 490-511. [CrossRef]

13. Hemberger, P.; Custodis, V.; Bodi, A.; Gerber, T.; Van Bokhoven, J.A. Understanding the mechanism of catalytic fast pyrolysis by unveiling reactive intermediates in heterogeneous catalysis. Nat. Commun. 2017, 8 , 1-9. [CrossRef] [PubMed]

14. Du, S.; Valla, J.A.; Bollas, G.M. Characteristics and origin of char and coke from fast and slow, catalytic and thermal pyrolysis of biomass and relevant model compounds. Green Chem. 2013, 15, 3214-3229. [CrossRef]

15. Ma, Z.; Ghosh, A.; Asthana, N.; van Bokhoven, J. Visualization of Structural Changes During Deactivation and Regeneration of FAU Zeolite for Catalytic Fast Pyrolysis of Lignin Using NMR and Electron Microscopy Techniques. ChemCatChem 2018, 10, 4431-4437. [CrossRef]

16. Hernando, H.; Hernández-Giménez, A.M.; Ochoa-Hernández, C.; Bruijnincx, P.C.; Houben, K.; Baldus, M.; Pizarro, P.; Coronado, J.M.; Fermoso, J.; Čejka, J.; et al. Engineering the acidity and accessibility of the zeolite ZSM-5 for efficient bio-oil upgrading in catalytic pyrolysis of lignocellulose. Green Chem. 2018, 20, 3499-3511. [CrossRef]

17. Lu, Q.; Wang, Z.; Guo, H.; Li, K.; Zhang, Z.X.; Cui, M.S.; Yang, Y.P. Selective preparation of monocyclic aromatic hydrocarbons from ex-situ catalytic fast pyrolysis of pine over $\mathrm{Ti}\left(\mathrm{SO}_{4}\right)_{2}-\mathrm{Mo}_{2} \mathrm{~N} / \mathrm{HZSM}-5$ catalyst. Fuel 2019, 243, 88-96. [CrossRef]

18. Lazaridis, P.A.; Fotopoulos, A.P.; Karakoulia, S.A.; Triantafyllidis, K.S. Catalytic Fast Pyrolysis of Kraft Lignin with Conventional, Mesoporous and Nanosized ZSM-5 Zeolite for the Production of Alkyl-Phenols and Aromatics. Front Chem. 2018, 6, 295. [CrossRef]

19. Ivanova, I.I.; Knyazeva, E.E. Micro-mesoporous materials obtained by zeolite recrystallization: Synthesis, characterization and catalytic applications. Chem. Soc. Rev. 2013, 42, 3671-3688. [CrossRef] [PubMed]

20. Jeon, M.; Jeon, J.; Jin, D.; Park, S.H.; Sa, Y.J.; Joo, S.H.; Park, Y.K. Catalytic pyrolysis of biomass components over mesoporous catalysts using Py-GC/MS. Catal. Today 2013, 204, 170-178. [CrossRef]

21. Hertzog, J.; Carré, V.; Jia, L.; Mackay, C.L.; Pinard, L.; Dufour, A.; Masšek, O.; Aubriet, F. Catalytic Fast Pyrolysis of Biomass over Microporous and Hierarchical Zeolites: Characterization of Heavy Products. ACS Sustain. Chem. Eng. 2018, 6, 4717-4728. [CrossRef]

22. Ding, K.; Zhong, Z.; Wang, J.; Zhang, B.; Addy, M.; Ruan, R. Effects of alkali-treated hierarchical HZSM-5 zeolites on the production of aromatic hydrocarbons from catalytic fast pyrolysis of waste cardboard. J. Anal. Appl. Pyrolysis. 2017, 125, 153-161. [CrossRef]

23. Qian, X.-F.; Li, B.; Hu, Y.-Y.; Niu, G.X.; Zhang, D.Y.H.; Che, R.C.; Tang, Y.; Su, D.S.; Asiri, A.M.; Zhao, D.Y. Exploring meso-/microporous composite molecular sieves with core-shell structures. Chem. A Eur. J. 2012, 18, 931-939. [CrossRef] [PubMed]

24. Diao, Z.; Wang, L.; Zhang, X.; Liu, G. Catalytic cracking of supercritical n-dodecane over meso-HZSM-5@Al-MCM-41 zeolites. Chem. Eng. Sci. 2014, 135, 452-460. [CrossRef]

25. Ren, X.-Y.; Cao, J.-P.; Zhao, X.-Y.; Yang, Z.; Liu, S.-N.; Wei, X.-Y. Enhancement of Aromatic Products from Catalytic Fast Pyrolysis of Lignite over Hierarchical HZSM-5 by Piperidine-Assisted Desilication. ACS Sustain. Chem. Eng. 2018, 6, 1792-1802. [CrossRef]

26. Cattelan, L.; Perosa, A.; Selva, M.; Yuen, A.K.; Lui, M.Y.; Masters, A.F.; Maschmeyer, T. Renewable Aromatics from Kraft Lignin with Molybdenum-Based Catalysts. ChemCatChem 2017, 9, 2717-2726. [CrossRef] 
27. Luo, Z.; Lu, K.; Yang, Y.; Li, S.; Li, G. Catalytic fast pyrolysis of lignin to produce aromatic hydrocarbons: Optimal conditions and reaction mechanism. RSC Adv. 2019, 9, 31960-31968. [CrossRef]

28. Li, S.; Luo, Z.; Wang, W.; Lu, K.; Yang, Y.; Liang, X. Characterization of pyrolytic lignin and insight into its formation mechanisms using novel techniques and DFT method. Fuel 2020, 262, 116516. [CrossRef]

29. Lu, K.; Hao, N.; Meng, X.; Luo, Z.; Tuskan, G.A.; Ragauskas, A.J. Investigating the correlation of biomass recalcitrance with pyrolysis oil using poplar as the feedstock. Bioresour. Technol. 2019, 289, 121589. [CrossRef]

30. Ciesielski, P.N.; Pecha, M.B.; Bharadwaj, V.S.; Mukarakate, C.; Leong, G.J.; Kappes, B.; Crowley, M.F.; Kim, S.; Foust, T.D.; Nimlos, M.R. Advancing catalytic fast pyrolysis through integrated multiscale modeling and experimentation: Challenges, progress, and perspectives. Wiley Interdiscip. Rev. Energy Environ. 2018, 7, 1-19. [CrossRef]

31. Cheng, Y.T.; Huber, G.W. Production of targeted aromatics by using Diels-Alder classes of reactions with furans and olefins over ZSM-5. Green Chem. 2012, 14, 3114-3125. [CrossRef]

32. To, A.T.; Resasco, D.E. Role of a phenolic pool in the conversion of m-cresol to aromatics over HY and HZSM-5 zeolites. Appl. Catal. A Gen. 2014, 487, 62-71. [CrossRef]

33. García, T.; Mitchell, S.; Pérez-Ramírez, J.; Puértolas, B.; Veses, A.; Callén, M.S. Porosity-Acidity Interplay in Hierarchical ZSM-5 Zeolites for Pyrolysis Oil Valorization to Aromatics. ChemSusChem 2015, 8, 3283-3293.

(C) 2020 by the authors. Licensee MDPI, Basel, Switzerland. This article is an open access article distributed under the terms and conditions of the Creative Commons Attribution (CC BY) license (http://creativecommons.org/licenses/by/4.0/). 